\title{
Knowledge of Disability Rights and the Social Encounters of Students with Disabilities in a Tertiary Institution in South Africa
}

\author{
A.K. Tugli ${ }^{1}$, L. I. Zungu' ${ }^{2}$, E. K. Klu ${ }^{3}$ and D. Ramathuba ${ }^{4}$ \\ ${ }^{1}$ Department of Public Health, University of Venda \\ E-mail: tugli.augustine@univen.ac.za \\ ${ }^{2}$ Department of Health Studies, University of South Africa \\ E-mail: zunguli@unisa.ac.za \\ ${ }^{3}$ Department of English, University of Venda \\ E-mail:asongkwesi@gmail.com \\ ${ }^{4}$ Department of Advanced Nursing. University of Venda \\ E-mail: dorah.ramathuba@univen.ac.za
}

KEYWORDS Learners with Disabilities. Rights. Encounter. Tertiary Institution

\begin{abstract}
This study explored the knowledge of disability rights among students with disabilities and their social encounters in a tertiary institution in South Africa. The study employed a descriptive cross-sectional quantitative design where self-administered questionnaires were used to collect data. Data were analysed using the Statistical Package for the Social Sciences (SPSS) version 19 as well as the Microsoft Excel. From the results, 50.7\% of the participants were males, and the majority $(41.8 \%)$ was morbidity impaired. Whilst at least $76 \%$ of the participants were aware of all disability rights, about a third $(31.3 \%)$ of the respondents reported being verbally abused as compared with other forms of abuses such as physical abuse $(4.5 \%)$ and sexual harassment $(3.0 \%)$. In addition, $37.3 \%$ of the participants indicated that they experienced stigmatization. Though the study found that an overwhelming majority (76\%) of participants were aware of all disability rights, but their social experiences greatly fell short of the rights they should be accorded. The study, therefore, recommends the need to design and embark on 'disability rights' awareness and enforcement programmes among the entire university institutions.
\end{abstract}

\section{INTRODUCTION}

People with disabilities are seen as an 'atrisk' population because of their venerability to poverty, abuse, lack of adequate education, poor access to health services and so on (HanassHancock et al. 2013) According to the United Nations (UN) (2006), persons with disabilities include those who have long-term physical, mental, intellectual or sensory impairments which in interaction with various barriers may hinder their full and effective participation in society on an equal basis with others. As a result of this, the concern of the United Nations for the well-being and rights of disabled persons is rooted in its founding principles, which are based on human rights, fundamental freedoms and equality of all human beings (UN 2004). In other words, persons with disabilities are entitled to exercise their civil, political, social and cultural rights on an equal basis with non-disabled persons.

In its preamble, the UN Convention on the Rights of Persons with Disabilities recognises the importance of accessibility to the physical, social, economic and cultural environment, to health and education and to information and communication, in enabling persons with disabilities to fully enjoy all human rights and fundamental freedoms (UN 2006).

UN (2006:1-15) spells out some of the key rights of persons with disabilities as:

- Equality and non-discrimination on all grounds (article 5)

- Ensuring that persons with disabilities access, on an equal basis with others, to the physical environment, to transportation, to information and communications, including information and communications technologies and systems, and to other facilities and services open or provided to the public, both in urban and in rural areas (article 9)

- Freedom from all forms of exploitation, violence and abuse, including their genderbased aspects (article 16)

- Participation in cultural life, recreation, leisure and sport (article 30)

- Adequate standard of living, social protection including adequate food, clothing and housing (article 28)

- Enjoy right to an inclusive education system at all levels and life long learning directed to full development of human potential and sense of dignity and self-worth (article 24) 
- Enjoyment of the highest attainable standard of health without discrimination on the basis of disability (article 24).

Notwithstanding all the above protective rights and guarantees, persons with disabilities often suffer from discrimination and other social violations (UN 2004). Ngwena (2013) argues that disability-related oppression, marginalization and socio-economic exclusion remain deeply rooted in African socio-economic systems.

According to the South African Human Rights Commission (SAHRC 2002) and the World Health Organisation (WHO 2011), people with disabilities experience unfair treatment and denial when it comes to equal access to health care, employment, services, education, or political participation. Alluding to the plight facing people with disabilities, World Bank (2005) posits that people with disabilities are always at the receiving end of violence, crime, abuse, prejudice and exploitation, eventually disability leads to poverty through a number of conscious and unconscious exclusion processes (Eide et al. 2013). In a nut shell, UN (2006) posits that discrimination on the basis of disability means any distinction, exclusion or restriction on the basis of disability which has the purpose or effect of impairing or nullifying the recognition, enjoyment or exercise, on an equal basis with others, of all human rights and fundamental freedoms in the political, economic, social, cultural, civil or any other field.

Fuller et al. (2004), Lawson et al. (2008) and WHO (2011) argue that disability need not be an obstacle to success; but regrettably, students with disabilities constantly face various challenges and barriers in their educational environment. In South Africa, students with disabilities have been identified in various governmental policy documents as being historically disadvantaged and deserving of special attention (Foundation of Tertiary Institutions of the Northern Metropolis (FOTIM) 2011). For this reason, many post-apartheid acts and policies were formulated and geared towards the promotion of the rights of people with disabilities. Despite these moves the majority of students with disabilities continue to experience violations of their rights in institutions of higher education and training sector (Department of Higher Education and Training (DHET) 2012).

Jacklin et al. (2007) in their study explored the educational and social experiences of learn- ers with disabilities in the context of one Institution of Higher Learning (IHE). The authors found that whilst the majority of the participants expressed that their learning and social experiences of higher education were positive, $12.5 \%$ said they were not happy with their social experiences. In their study, Tinklin et al. (2004) and Weedon et al. (2008) identified that disclosure and acceptance of the label of 'disability' was problematic for some students, especially those with hidden impairments who wanted to pass as non-disabled and, did not tell other students, or lecturers about their impairment. Obiozor et al. (2010) argue that a major reason for not disclosing their disabilities could be to avoid labeling and social stigmatization. In another study to explore the views of students regarding the social and learning environment of students with disabilities at one of the disadvantaged universities in Limpopo Province, Ramakuela and Maluleke (2011) revealed that the majority $(80 \%)$ of students with disabilities feel rejected by their fellow non-disabled students, staff and the institution. Among other encounters reported in the study included non-acceptance, hostility, abusive attitudes and lack of respect for the autonomy of students with disabilities.

Against this background, the study sought to explore the knowledge of disability rights among the students with disabilities and their social encounters in a tertiary institution in the Limpopo Province, South Africa.

\section{MATERIAL AND METHODS}

\section{Study Design}

The study adopted a quantitative approach by employing a descriptive cross-sectional design to explore and describe the knowledge of disability rights among students with disabilities and their social encounters. According to Burns and Grove (2009), this design seeks to determine the current status of population characteristics at one point in time while also attempting to discover the relationships among variables.

\section{Population and Sample}

The target population for this study comprised of all students with disabilities who were registered for undergraduate and post-graduate 
programmes at the University of Venda during the 2011 academic year. This population cuts across all disability groups and schools. Due to the small number involved and to avoid excluding some disability categories in the study, the researcher used a total population study. This gave equal chance to any registered students with disabilities to be part of the study.

\section{Instrument and Data Collection Procedure}

A structured questionnaire was developed based on the World Health Organization Disability Assessment Schedule (WHODAS 2011). The questionnaire comprised of sections that captured demographic information as well as sections on disability rights and social experiences with both closed and open-ended questions. To ensure validity of the instrument a wide range of literature and experts were consulted. The instrument was further pre-tested on three students with disabilities who volunteered to take part in this exercise. Pre-testing results were used to rephrase and modify some aspects of the instrument. Above all, the instrument was administered to all students with disabilities who consented to participate in the study.

\section{Ethical Consideration}

The researchers were granted ethical clearance approval by the Research Ethics Committee of the department of Health Studies at the University of South Africa to conduct the study. In addition, the researchers obtained an internal ethical clearance approval from the Research and Innovation Directorate of the University of Venda. Since the study involved learners with disabilities, permissions to conduct the study were also received from the Center for Higher Education, Teaching and Learning (CHETL) office and the Disability Unit of the institution. Besides adhering to the principles of voluntary participation and informed consent, participants were also made to fill in the consent forms and were also guaranteed confidentiality of their responses and anonymity of their identities.

\section{Data Analysis}

Burns and Grove (2009) describe data analysis as a process conducted to reduce, organize, and give meaning to data. The Statistical Pack- age for the Social Sciences (SPSS) version 19 and the Microsoft Excel were used to perform the analysis of the data. Data were summarized and presented in pictorial, tabular and graphical format.

\section{RESULTS}

\section{Socio-demographic Profile of the Participants}

A total of 67 participants took part in the study of which $34(50.7 \%)$ were males and $33(49.3 \%$ ) females. Out of this figure, $56(84.8 \%)$ hailed from the Limpopo province, $8(12.1 \%)$ from Mpumalanga, 1(1.5\%) from Gauteng and 1(1.5\%) Kwa-Zulu Natal provinces. In the study, the mean age was $26.58 \pm 4.69$ years with the minimum and maximum ages being 19 years and 44 years respectively. Among the participants, the majority $(n=28,41.8 \%)$ were mobility impaired, and this was followed by visually impaired group $(n=20,29.9 \%)$. The disability categories also comprised of $9(13.4 \%)$ albinism and $3(4.5 \%)$ of participants having multiple disabilities which include asthma and bipolar mood disorder.

\section{Knowledge about Disability Rights}

The respondents' knowledge about disability rights was explored and the results are shown in Table 1. As far as the disability rights were concerned, all $(n=67,100.0 \%)$ of the respondents stated they were aware of the right not to be discriminated against. Other rights most popularly known by the respondents include the right to health and rehabilitation $(n=65,97.0 \%)$, inclusive education $(n=65,97.0 \%)$ and the right to participate in social life and relationships $(\mathrm{n}=62$, $96.9 \%)$. However, nearly a quarter $(n=16,23.9 \%)$ of the respondents indicated they did not know of the right to adapted built environment.

\section{Social Encounters}

The social encounters of students with disabilities are depicted in Figure 1. In the figure about a third $(32.8 \%)$ of the participants reported being verbally abused as compared with other forms of abuse such as physical abuse (4.5\%) and sexual harassment (3.0\%). Although about three quarters $(74.2 \%)$ of the participants reported that they enjoyed special treatment as a result of their disabilities, $37.3 \%$ and $32.8 \%$ indi- 
Table 1: Knowledge of disability rights

\begin{tabular}{|c|c|c|c|c|}
\hline \multirow{2}{*}{ Disability rights } & \multicolumn{3}{|c|}{ Responsesn(\%) } & \multirow[t]{2}{*}{ Total } \\
\hline & & Yes & No & \\
\hline Right to social life and relationships & 62 & $(96.9 \%)$ & $2 \quad(3.1 \%)$ & $64(100.0 \%)$ \\
\hline Right to free communication and assistive devices & 63 & $(94.0 \%)$ & $4 \quad(6.0 \%)$ & $67(100.0 \%)$ \\
\hline Right not to be abused & 64 & $(95.5 \%)$ & $3 \quad(4.5 \%)$ & $67(100.0 \%)$ \\
\hline Right to adapted built environment & 51 & $(76.1 \%)$ & $16(23.9 \%)$ & $67(100.0 \%)$ \\
\hline Right to affordable and adequate transport & 51 & $(78.5 \%)$ & $14(21.5 \%)$ & $65(100.0 \%)$ \\
\hline Right to housing & 59 & $(88.1 \%)$ & $8(11.9 \%)$ & $67(100.0 \%)$ \\
\hline Right to sports and recreation & 63 & $(94.0 \%)$ & $4 \quad(6.0 \%)$ & $67(100.0 \%)$ \\
\hline Right to employment and assistance & 61 & $(91.0 \%)$ & $6 \quad(9.0 \%)$ & $67(100.0 \%)$ \\
\hline Right to inclusive education & 65 & $(97.0 \%)$ & $2(3.0 \%)$ & $67(100.0 \%)$ \\
\hline Right to health and rehabilitation & 65 & $(97.0 \%)$ & $2(3.0 \%)$ & $67(100.0 \%)$ \\
\hline Right to self-representation & 57 & $(85.1 \%)$ & $10(14.9 \%)$ & $67(100.0 \%)$ \\
\hline Right not to be discriminated against & 67( & $(100.0 \%)$ & $0 \quad(0.0 \%)$ & $67(100.0 \%)$ \\
\hline Right to social grants & 61 & $(91.0 \%)$ & $6 \quad(9.0 \%)$ & $67(100.0 \%)$ \\
\hline
\end{tabular}

cated that they experienced discrimination and stigmatisation as well as feelings of insecurity and being unsafe respectively. While $46.3 \%$ of the participants agreed to having confidence in their confidants, $22.4 \%$ reported in the affirmative that they experienced depression or selfpity as a result of their disabilities. In addition, almost a quarter $(25.4 \%)$ of the participants stated that they were feeling isolated while $30.3 \%$ reported that they felt they were being exploited because they had disbailities.

\section{DISCUSSION}

The majority $(84.8 \%)$ of the participants hailed from the Limpopo province and among them the majority (46.3\%) came from the Vhembe District where the study was conducted. Even

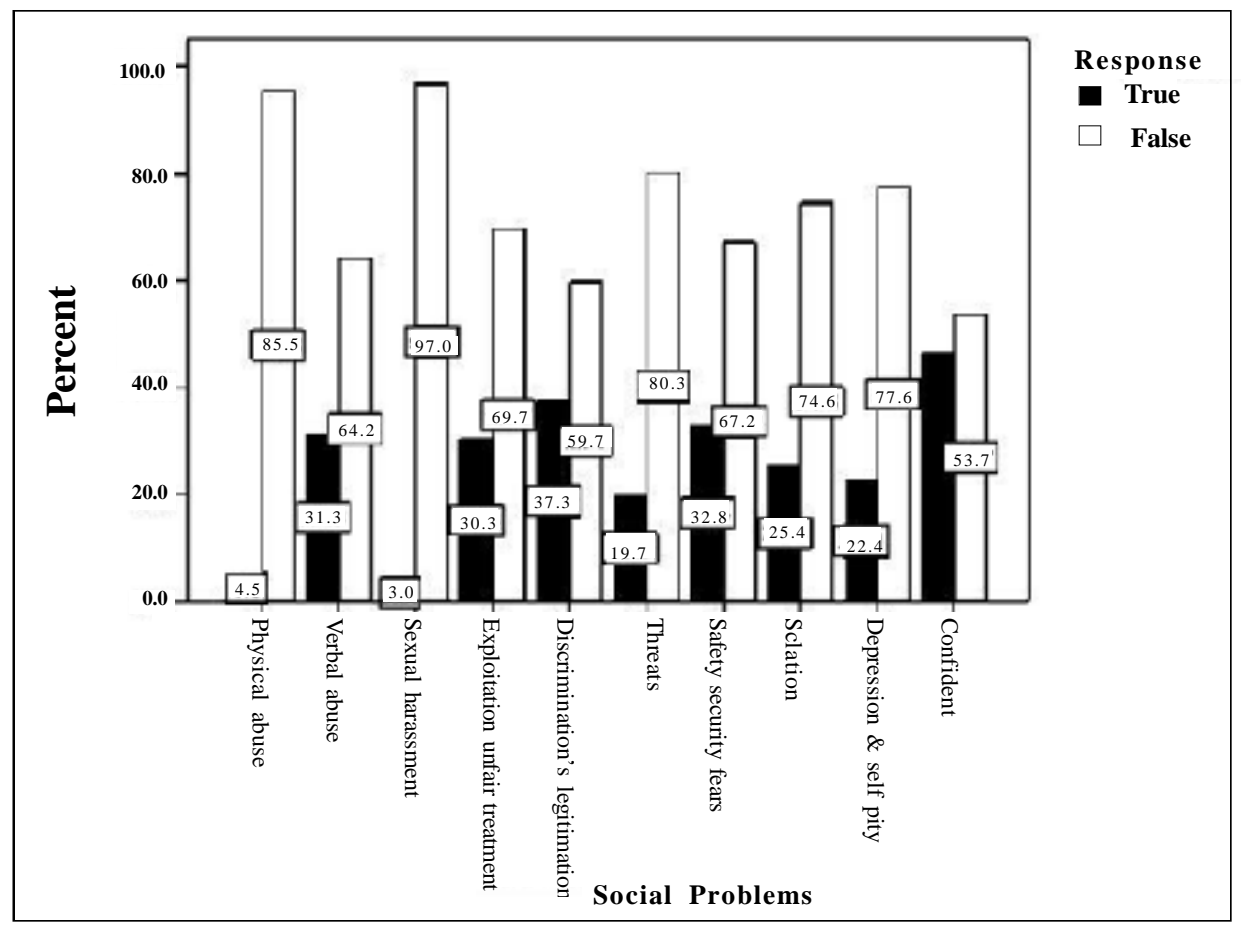

Fig. 1. The Distribution of students with disabilities according to their social problems 
though University of Venda serves quite a number of learners from the neighbouring countries such Zimbabwe, Botswana and Mozambique as well as other foreign countries, it is quite surprising to note that none of the participants hailed from countries other than South Africa. The mean age of the participants was 26.6years which indicates a youthful sample, and above that, the sample had a fair gender mix and representation (50.7\% males and $49.3 \%$ females). This is consistent with the 50:50 gender representation reported in another study by Hall and Healey (2004).

Though UN (2004) acknowledges that persons with disabilities are entitled to exercise their civil, political, social and cultural rights on an equal basis with non-disabled persons, it is also imperative on the part of persons with disabilities to know their rights. As far as the disability rights are concerned, all $(100.0 \%)$ the participants stated they knew of the right not to be discriminated against. Other rights most popularly known by the participants include the right to inclusive education $(97.0 \%)$ and the right to participate in social life and relationships (96.9\%). Though nearly a quarter $(23.9 \%)$ of the participants indicated they did not know of the right to adapted built environment it is very encouraging to note that more than $76.0 \%$ of the participants are aware of all the disability rights. Knowledge is power; however, it is one thing having knowledge about disability rights but it is quite another thing enjoying these rights or being accorded the rights that one is entitled to.

Social problems can pose a formidable stumbling block in the self-development, self-actualization and the development of the full potentials of students with disabilities. The responses gathered from participants on questions based on their social encounters in the institution revealed that about a third $(32.8 \%)$ of the participants reported being verbally abused as compared with other forms of abuses such as physical abuse $(4.5 \%)$ and rape $(3.0 \%)$. Almost 2 in $5(38.5 \%)$ and nearly 1 in $3(32.8 \%)$ participants indicated they experienced discrimination and safety fears respectively. The study also found that about 1 in $4(25.4 \%)$ participants feel isolated. In contrast, Ramakeula and Maluleke (2011) reported a higher proportion $(80.0 \%)$ of participants who felt or rejected by their fellow students, staff and the university system.
Freedom from all forms of exploitation, violence and abuse, including their gender-based aspects are enshrined in Article 16 of the UN Convention on the Rights of Persons with Disabilities (UN 2006). The message at this convention is to view disability from a different perspective. Thus, Ngwenya (2013) points out that a shift from traditional ways of looking at disability as individual impairment to focusing on ways of creating an enabling environment is vital. It is, therefore, disturbing to note in this study that the rights of a vulnerable group such as students with disabilities are grossly violated in a number of ways. This is an indication of an intolerant society that is not accepting the phenomenon of disability as an integral part of human nature. This attitude will give rise to further marginalization of persons with disabilities and suppress disclosure of disabilities especially hidden disabilities. Tinklin et a. (2004) and Weedon et al. (2008) alluded to this in their studies by arguing that disclosure and acceptance of the label of 'disability' will continue to be problematic for some students with disabilities if violations reported above are allowed to continue with impunity.

\section{CONCLUSION}

From the findings of this study, it can be seen that there is a wide gap between the disability rights on one hand and their application and practice on the other hand. What students with disabilities face in terms of their social encounters vis a vis the so called " rights of persons with disabilities" in the current learning environment gives an indication that the realisation of the ideals of the Universal Declaration of Human Rights and Convention on the Rights of Persons with Disabilities are still a long way off.

\section{RECOMMENDATIONS}

The study recommends the need to design and embark on 'disability rights' awareness programmes among the entire university using various dissemination and information formats.

\section{REFERENCES}

Burns N, Grove SK 2009. The Practice of Nursing Research. Missouri: Saunders Elsevier. 
Department of Higher Education and Training (DHET) 2012. Green Paper for Post-School Education and Training. Pretoria: Government Printer.

Foundation of Tertiary Institutions of the Northern Metropolis (FOTIM) 2011. Disability in Higher Education. South Africa: FOTIM.

Eide AH, Ingstad B 2013. Disability and poverty Reflections on research in Africa and beyond. African Journal of Disability, 2(1): 1- 7 .

Fuller M, Healey M, Bradley A, Hall T 2004. What are disabled students' experiences of learning at university. Studies in Higher Education, 29(3): 303318.

Hall T, Healey M 2004. The Experience of Living at University by Disabled Students in Geography, Earth and Environmental Sciences and Related Disciplines. Gloucestershire: University of Gloucestershire.

Hanass-Hancock J, Regondi I, Naidoo K 2013. Disability and HIV: What drives this relationship in Eastern and Southern Africa. African Journal of Disability, 2(1): 1- 6 .

Jacklin A, Robinson C, O'mera L, Harris A 2007. Improving the Experiences of Disabled Students in Higher Education. East Sussex: The Higher Education Academy.

Lawson K, Werth S, Dunn D, Abadie O 2008. The Impact of Disabilities and Long-Term Medical Conditions on the Student Learning Experience at the University of Southern Queensland (USQ). Sofitel Meibourne: USQ.

Ngwena C 2013. African Disability Rights Yearbook. From <http://www.pulp.up.ac.za/pdf/2013_07/ 2013 07.pdf.> (Retrieved on 07 February 2014).

Obiozor WE, Onu VC, Ugwoegbu I 2010. Academic and social challenges facing students with developmental and learning disabilities in higher institutions:
Implications to African Colleges and Universities. African Journal of Teacher Education, 1(1): 126140

Ramakuela NJ, Maluleke TX 2011. Students' views regarding the social and learning environment of disabled students at the University of Venda, South Africa. African Journal for Physical, Health Education, Recreation and Dance, 2(1): 285-294.

South African Human Rights Commission (SAHRC) 2002. Towards a Barrier-Free Society. Johannesburg: SAHRC.

Tinklin T, Riddell S, Wilson A 2004. Disabled Students in Higher Education. Edinburgh: Centre for Educational Sociology-University of Edinburgh.

United Nations (UN) 2004. The UN and Persons with Disabilities. Geneva: UN Department of Economic and Social Affairs and Division for Social Policy and Development.

United Nations (UN) 2006. The Convention on the Rights of Persons with Disabilities. Geneva: Department of Public Information.

Weedon E, Riddell S, Fuller M, Healey M, Kelly K, Georgeson J, Roberts H 2008. Disabled Students in Higher Education: Experiences and Outcomes. London: Routledge.

World Bank 2005. A Note on Disability Issues in the Middle East and North Africa (NENA) the World Bank. Washington, D.C.: World Bank

World Health Organisation (WHO) 2011. World Report on Disability. Malta: WHO Library Cataloguing-in-Publication Data.

World Health Organisation Disability Assessment Schedule (WHODAS) 2011. WHO Disability Assessment Schedule 2.0. From <http://www.who.int/ classifications/icf/whodasii/en/index.html.> (Retrieved on 27 December 2011). 